\title{
CONCRETIZAÇÃO DA CIDADANIA AMBIENTAL A PARTIR DO PODER LOCAL: UMA INTERLOCUÇÃO NECESSÁRIA AO DESENVOLVIMENTO SUSTENTÁVEL
}

\author{
João Telmo Vieira* \\ Priscila Rettenmaier Garibald**
}

\section{RESUMO}

A importância da temática da proteção ambiental justifica sua discussão e divulgação junto à comunidade científica. Nesse sentido, propõe-se no presente estudo investigar em que medida a descentralização - almejando uma democracia participativa, com sólidas estruturas locais - pode favorecer a concretização de uma cidadania ambiental que remeta ao desenvolvimento sustentável. Visa-se, dessa maneira, alcançar o propósito de uma gestão sustentável que garanta o direito das presentes e futuras gerações a um meio ambiente equilibrado através da interlocução entre Estado e sociedade.

Palavras-Chave: Cidadania. Democracia. Descentralização. Desenvolvimento Sustentável. Poder Local.

\section{INTRODUÇÃO}

Nas últimas décadas, um dos maiores desafios da humanidade tem sido a crise ecológica global. Na busca pela felicidade, o homem moderno dominou - meio, revolucionando constantemente os meios de produção e negligenciando a relação de interdependência entre ser humano e natureza. Desta forma impensada e excludente de agir, colhem-se hoje os frutos.

A sociedade, agora certa dos limites do conhecimento científico e não mais confiante que a técnica tudo pode solucionar, e colocando em cheque as próprias instituições de pesquisa, passa a viver em uma era de incertezas, em que não se pode impor a tolerância aos riscos do desenvolvimento. Neste ambiente de discussão da sociedade de risco ${ }^{1}$, surge o debate acerca do desenvolvimento sustentável.

Mas ao mesmo tempo em que essa discussão tem impulsionado a criação de novos arranjos institucionais, a disseminação em escala global do neoliberalismo propicia um clima favorável a um discurso que prega 0 desenvolvimento econômico a qualquer custo. Tanto internacional quanto nacionalmente, o sistema político não se tem mostrado preparado a transformar as demandas sociais em políticas públicas para um desenvolvimento alternativo. O cerne da questão está, pois, em concatenar interesses de uma economia mundial com o uso consciente e não predatório do meio ambiente. 
Neste contexto, em que se busca garantir qualidade de vida às presentes e às futuras gerações sem frear o desenvolvimento científico e tecnológico, acredita-se que o desafio da sustentabilidade não se restringe ao mero gerenciamento dos recursos naturais, mas engloba, sobretudo, questões políticas. Por essa razão, o objetivo é investigar até que ponto a descentralização pode auxiliar na concretização de uma cidadania ambiental, enquanto importante instrumento para o desenvolvimento sustentável.

Para isso, primeiramente buscar-se-á compreender o paradoxo da busca pela sustentabilidade em sociedades marcadas pelo neoliberalismo, para após aprofundar-se o estudo quanto à formulação de uma cidadania ambiental capaz de concretizar políticas ambientais. Por fim, trazem-se à tona algumas questões recorrentes quanto à descentralização, ressaltando a autonomia e competência municipal em matéria ambiental. Com isso, acreditase ser possível contribuir para a discussão, mas principalmente para a ação efetiva que garantirá qualidade de vida à sociedade como um todo.

\section{DESENVOLVIMENTO SUSTENTÁVEL $X$ MERCADO: UMA MUDANÇA DE PARADIGMA}

Para que se possa analisar o paradoxo na busca do desenvolvimento sustentável em sociedades cujo modelo econômico caracteriza-se por ser neoliberal $^{2}$, é preciso primeiramente definir 0 que se entende por sustentabilidade, dentro de uma perspectiva de conservação dos recursos naturais. Em sua primeira aparição, revelou-se como um princípio diretor para o planejamento do desenvolvimento econômico pela World Commission on Environment and Development (WCED) em 1987. De acordo com o prescrito neste documento, seria sustentável todo desenvolvimento que não comprometesse a capacidade das futuras gerações em satisfazer suas necessidades.

No relatório Brundtlandt, encomendado pela Assembléia Geral da ONU em 1983, a seguinte definição é encontrada: "o desenvolvimento sustentável pretende satisfazer as necessidades do presente sem comprometer os recursos equivalentes de que farão uso no futuro outras gerações". ${ }^{3}$ Ínsito está, pois, que a natureza só poderia ser modificada com o intuito de garantir a manutenção da vida humana ou quando fosse possível utilizar-se dos bens sem prejudicar sua (re)produção. Complementando essa definição, Mateo assevera que "a indústria sustentável requer uma transformação da cultura empresarial, que somente pode ser conseguida através de uma ampla interação entre indústria e outros valores da sociedade"4. Ao que acrescenta a necessidade da justa distribuição de riquezas.

É neste ponto que surge a contradição: os modelos econômicos neoliberais das sociedades atuais, com seus hábitos de consumo e produção, comprometem a sustentabilidade dos ecossistemas, estabelecendo um círculo vicioso entre sistemas naturais e sociais. O homem, cada vez mais crente de sua superioridade $e^{5}$ perante 0 meio, alimenta com sua postura individualista a fome insaciável por lucros do mercado econômico, que se encontra em 
constante adaptação com o intuito de aumentar seu poder de sedução perante o consumidor.

As pessoas, que passaram a cultuar o ter em detrimento do ser na busca pela felicidade, vêm se entregando a um consumismo desvairado, que há muito deixou de ser razoável. Quanto maior o consumo, maior é a atuação do mercado na busca pelo incremento de seus produtos, que ocasionará, por conseguinte, o frenesi dos consumidores. Avritzer conclui com propriedade que "sequer na condição de consumidor o indivíduo moderno consegue formar sua vontade independentemente dos mecanismos de publicidade e de persuasão"6. Souza vê este fenômeno como uma "máquina diabólica" que apresenta uma vinculação estrutural entre quatro variáveis, quais sejam: extensivo da natureza, [...] infinita em sua generosa oferta de energia e matérias-primas [...];
a) Modelo aceito de desenvolvimento com base no uso intensivo e
b) Sistema desejado de vida, sem caráter classista, [...] orientado para o consumo crescente e novas comodidades acumuladas $[\ldots]$
c) Constelação de valores dominantes, a legitimar este sistema devido à evidência de avanços dos níveis de vida e dos recursos técnicos postos à disposição da sociedade, [...] anestesiando a consciência do dano por formar utopias tecnológicas quanto ao futuro;
d) Desatenção coletiva para com os aspectos negativos devido ao fascínio da massa pelo positivo. ${ }^{7}$

No entanto, a vertente do pensamento neoliberal parte do pressuposto da necessidade de crescimento econômico como garantia para a redução da pobreza, que seria responsável pela deterioração do meio ambiente. Conforme Derani, "só é possível o desenvolvimento sustentável durante um período de prosperidade econômica"8. A pressão da concorrência, o crescimento econômico e a prosperidade impulsionariam o uso racional dos recursos naturais e as novas necessidades de consumo compatíveis com as exigências ambientais. ${ }^{9}$ Acreditam que o mercado responderia com a oferta de produtos ecológicos à medida que os consumidores manifestassem sua consciência ecológica. ${ }^{10}$

Essa abordagem prioriza nitidamente o crescimento econômico em detrimento do meio ambiente, pois se apóiam "no postulado de que crescimento constante da economia é necessário para expandir-se o bem-estar pelo mundo"11. Por conseguinte, não houve a imposição, por parte das nações dominantes, de qualquer obstáculo à proposta do relatório Brundtlandt de desenvolvimento sustentável, ou seja, a mesma tornou-se aceitável. Afinal, esse relatório não oferece propostas concretas que modifiquem os mecanismos de produção em voga.

Entretanto, os teóricos que defendem esse posicionamento não respondem a um questionamento: se o desenvolvimento da atividade econômica resulta no consumo de recursos, como se alcançará o ideal de diminuição deste mesmo consumo sem que o desenvolvimento seja 
prejudicado $?^{12}$ Como defende Milaré, "o consumo não sustentável também está na origem de muitos dos nossos males ambientais"13.

O atual modo de produção, sempre em busca do mercado consumidor, justifica uma "pseudo-necessidade" de contínuo crescimento, considerando os recursos naturais como inesgotáveis. Partindo a economia, pois, da dominação e transformação da natureza, depende a mesma da disponibilidade dos recursos naturais. O cerne da questão está, assim, em encontrar uma maneira de conciliar economia e ecologia, equilibrando "riqueza coletiva existente e esgotável com riqueza individual e criável"14.

Está-se, então, diante do desafio de coordenar práticas individuais com interesses coletivos. Nesse sentido, Klaus Frey adverte que:

Sendo que os custos do uso dos bens comuns se distribuem ao grupo como um todo e a parte individual dos custos totais fica menor do que o benefício individual - o qual o indivíduo pode usufruir inteiramente por si mesmo - torna-se racional para cada indivíduo do grupo seguir uma estratégia de ilimitada ampliação da sua própria parte do bem comum. ${ }^{15}$

Diante desse cenário, é possível vislumbrar que a questão ambiental deve ser tida principalmente como um problema político, onde interesses difusos não encontram adequada representação nas decisões políticas por serem contraditórios aos interesses do modelo econômico vigente.

Por isso, a apropriação dos bens naturais evoca a revisão das dicotomias público-privado e estado-sociedade. $\mathrm{O}$ direito a um meio ambiente sadio, dessa forma, não tem referência imediata nem a titulares estatais nem a titulares privados. A partir do reconhecimento da inconveniência dessa separação, abre-se caminho para a disseminação de novos valores e pressupostos que valorizam os processos decisionais a partir das bases da sociedade, em uma nova abordagem política de participação democrática.

Para alguns teóricos simpatizantes da abordagem ecológico-tecnocrata, é certo que a intervenção estatal, por meio de planejamento, torna-se indispensável para minimizar os efeitos nocivos dos processos de crescimento econômico. Nusdeo alerta para o fato de que não há verdadeiro progresso com a deterioração da qualidade de vida, assim como é ilusório qualquer desenvolvimento à custa de degradação ambiental ${ }^{16}$. A meta principal desse planejamento deve, pois, ser a harmonização dos interesses econômicos e ecológicos. Para atingir esse objetivo, Sachs destaca que

[...] o planejamento terá que ser participativo e político, o que o situa em oposição ao planejamento tecnocrático e pretensamente neutro, convencido de que o desenvolvimento se autoprivilegia e que, ademais, pode tornar-se ótimo tão-somente pela intervenção do escalão central. ${ }^{17}$

Para Klaus Frey, essa proposta de ecodesenvolvimento se aproxima da abordagem política de participação democrática, que será analisada em momento oportuno. No entanto, o ponto de partida daquela é uma nova 
concepção de desenvolvimento em que a participação popular é um instrumento de planejamento; enquanto 0 da última são as próprias contradições e falhas do sistema e dos processos político-administrativos. ${ }^{18}$

\section{CIDADANIA AMBIENTAL: A SUSTENTABILIDADE A PARTIR DA PARTICIPAÇÃO DEMOCRÁTICA}

Em virtude da incapacidade do Estado - baseado no modelo predominante do neoliberalismo - em oferecer à sociedade uma resposta adequada às demandas ambientais, observa-se o surgimento de uma vertente que almeja a transferência para os sistemas da sociedade civil de maiores responsabilidades, bem como do aumento de informação e da possibilidade de controle pela mesma. Evidentemente, essa teoria demonstra a desilusão para com o potencial do Estado em atender os anseios sociais. Ratificando o exposto, Derani defende que

[...] instrumentos de participação direta da sociedade são necessários. A atuação democrática concreta dos cidadãos é o que resta para ocupar o lugar do pingue-pongue entre estatismoliberalismo. Tais instrumentos devem possibilitar a consecução de um bem-estar social calcado no conceito de comunidade. ${ }^{19}$

Nessa abordagem, o planejamento deve ser conduzido pela comunidade e não apenas orientado pelas suas necessidades. Para isso, Klaus Frey propugna pela necessidade de rompimento com o "compromisso de elite através da descentralização do processo de decisão e da introdução de uma democracia participativa", e não meramente representativa. ${ }^{20}$

Deste ângulo, torna-se imprescindível uma democratização ecológica que requer a proliferação de valores democráticos e ao mesmo tempo de valores ecológicos, ou seja, tanto a democratização do processo político como a ecologização das políticas públicas. ${ }^{21}$

A compreensão desta democratização ecológica perpassa obrigatoriamente pela análise da cidadania. Afinal, como salienta Reilly, "a democratização se constrói sobre a cidadania assim como a formulação do capital social para o desenvolvimento"22. Como cidadania clássica, Morato Leite e Ayala apontam a conjunção da cidadania civil, política e social. Referem-se elas, respectivamente, às liberdades individuais, ao direito de exercício do poder político, e à cobrança por uma ação positiva do Estado que considere o bem-estar social. ${ }^{23}$

Vieira, por sua vez, já compreende a civilidade como "a atitude individual de preocupação com o bem público, transmitindo a idéia de espírito público que se perdeu na sociedade de mercado". Seria, pois, "a conduta de uma pessoa cuja autoconsciência individual está parcialmente sobre-determinada por sua autoconsciência coletiva". ${ }^{24}$ Percebe-se, portanto, a proposta de uma cidadania com maior ênfase na responsabilidade.

A reconstrução do conceito de cidadania, que espera da sociedade maior engajamento político nas questões que lhes são atinentes, conduz à 
formação de um sentido diverso a desembocar em uma "cidadania ambiental". Essa alteração, pretendida no modelo de cidadania vigente, exprime claramente o sentido de identidade e integração de uma "nova racionalidade ambiental". Essa, por sua vez, exigiria a participação efetiva dos sujeitos afetados pelas decisões, mesmo que apenas em potencial, na fiscalização do procedimento e na própria formação da vontade ao decidir. ${ }^{25}$

A participação do cidadão no poder com plena colaboração, para Baracho, configura-se uma das principais características da democracia. Têmse, pois, a liberdade e a democracia como requisitos indispensáveis ao exercício da cidadania. ${ }^{26}$

A inclusão da participação, na ótica de Morato Leite e Ayala traria conseqüências negativas e positivas. As negativas expressariam a insuficiência do modelo neoliberal que condicionou a noção de cidadania ao aspecto meramente político. ${ }^{27}$ Por seu turno, as conseqüências positivas contribuíram à elaboração de um modelo de cidadania que se poderia dizer renovado, compatível com um Estado de Direito do Ambiente. ${ }^{28}$

O que doutrinadores como Morato Leite e Ayala propõem é uma ruptura com a proposta democrática clássica, que estabelece restrições à abertura participativa. Nesse sentido, ensina Vieira que "uma sociedade multicultural só pode manter-se unida se a cidadania democrática não se limitar à visão liberal dos direitos políticos, expandindo-se para abranger direitos culturais e sociais" ${ }^{\prime 2}$.

Igualmente, não se pode descurar que essa nova cidadania, a que Morato Leite e Ayala denominam de ambiental, possui maior abrangência, não restando circunscrita espacialmente a um determinado território ou, ainda, estabelecendo alguma relação a um determinado povo, que fosse oriundo da significação clássica de nação. Seu objetivo, ao contrário, é a proteção intercomunitária do bem difuso ambiental, renegando os elementos referidos na cidadania clássica. ${ }^{30}$

Atendendo a isso, pode-se afirmar que o cidadão nesse modelo de cidadania não possui qualquer compromisso de lealdade nacional, mas sim, de lealdade ecológica, que poderá, inclusive, ser transnacional em virtude da extensão dos danos que podem advir. Não pareceria compatível que atores sociais globalizados ficassem sob o jugo de amarras nacionais. De tal sorte que, momentaneamente, a cidadania ambiental surge como a resposta por excelência para essa nova estrutura social.

Cabe, destarte, à democracia ambiental, garantir que direitos de gerações futuras sejam preservados, a partir da reserva da decisão à participação de seus legítimos interessados. Esse procedimento não pode ser visto como um limitador do processo democrático atual, mas tão somente como uma reserva para apreciação futura e pertinente de problemas pontuais com os interessados diretos. ${ }^{31}$ 
Mesmo a Constituição Federal de 1988, em seu artigo 225, ao delinear um sistema de responsabilidades partilhadas entre todos, reconheceu na cidadania ambiental uma orientação inclusiva, tanto daqueles indivíduos que estariam privados de exercer regularmente seus direitos políticos, quanto das futuras gerações. Nesse sentido, Sáiz destaca que "o processo de tomada de decisões políticas deve estar acompanhado de um reconhecimento público de que os efeitos da atividade humana sobre o meio ambiente vão mais além da distância do tempo"32.

Por essa razão, e pela necessidade do exercício da cidadania se dar de forma globalizada, para Morato Leite e Ayala, o Estado de Direito Ambiental deve privilegiar o exercício da cidadania coletiva. Com esse procedimento, permite-se que se exerça maior pressão e que reivindicações tenham, conseqüentemente, mais força, sem, é claro, desprezar a cidadania individual. ${ }^{33}$

Levando em consideração que ainda hoje o Estado atua de forma excludente, priorizando o econômico e negligenciado o exercício da responsabilidade partilhada, cresce em importância o papel desempenhado pelos movimentos sociais. Sua relevância para a democratização dos sistemas políticos com novas formas organizacionais se reflete com a publicização de temas até então da esfera privada.

Um marco fundamental nesse processo se deu com a Rio-92, Cúpula para - Desenvolvimento Sustentado, que passou a incorporar as vozes dos cidadãos nas agendas de debates governamentais, em uma interlocução entre Estado e sociedade. Entretanto, Reilly lamenta que recaia sobre a sociedade civil o peso da cidadania em detrimento do Estado. ${ }^{34}$ Como defende Andrade, tais

Grupos e classes tornam-se cada vez mais protagonistas da ação social e política, indicando que os conflitos extrapolam sua dimensão interindividual para alcançar uma dimensão interclassista e intergrupal: o impasse entre o individual e o coletivo (social) inscrevese no horizonte de possibilidade da cidadania. ${ }^{35}$

Cidadania essa que se encontra distante, quiçá seja utópica, em face da crise por que passam as estruturas sociais. Uma mudança de paradigma de Estado, com repolitização de seu povo é medida urgente. Boaventura acredita que se deve buscar uma sociedade menos volúvel aos desmandos do mercado, mais solidária e fraterna, com transformação nos modos de produção e de consumo. ${ }^{36}$

Mas para que esse objetivo possa ser alcançado, é imprescindível que se invista em educação ambiental, por ser um dos meios mais eficazes na persecução de maior conscientização. Leonardo Boff defende essa bandeira quando afirma que "para cuidar do planeta precisamos todos passar por uma alfabetização ecológica e rever nossos hábitos de consumo. Importa desenvolver uma ética do cuidado" ${ }^{137}$. 
Para Nalini, o desafio posto "é sensibilizar as consciências, fazer com que todos sejam alertados sobre as conseqüências de seus atos" ${ }^{\prime \prime 2}$, em um momento social em que o individualismo impera, e que a busca por ostentação (na tentativa de se alcançar a felicidade) alimenta o mercado econômico e estimula o consumismo egoísta e desvairado.

Ressalte-se, porém, que de nada adiantará um povo com consciência ecológica se ao mesmo não forem prestadas informações. Nesse sentido, é preciso garantir o acesso da comunidade aos debates e às decisões atinentes aos riscos ambientais. Essa medida de submeter os processos de decisão ao controle público (pela sociedade, maior interessada) objetiva, outrossim, prevenir e/ou minimizar os efeitos oriundos de falhas técnicas, das quais possam eclodir perigos à humanidade.

Para a concretização de uma verdadeira cidadania ambiental, Mirra sustenta a junção de três mecanismos, quais sejam: a participação na criação do direito ambiental, a participação na formulação e execução de políticas ambientais e a participação através do Poder Judiciário (geralmente com fins reparatórios, e algumas vezes preventivos). ${ }^{39}$ Por acreditar que tal junção é viável com a descentralização, algumas considerações sobre autonomia e competência municipal se fazem necessárias.

\section{MUNICÍPIO: UM ESPAÇO AUTÔNOMO DE CONCRETIZAÇÃO DE POLÍTICAS AMBIENTAIS}

Hoffmann-Axthelm, citado por Klaus Frey, estabelece o conceito de ecologia do sujeito e de ecologia global. Entende o primeiro como a preocupação que cada indivíduo tem com seu próprio ambiente. É sua característica que o sujeito não se sinta atingido pessoalmente pela destruição ambiental. A ecologia global, ao contrário, é vista pelo autor como uma ecologia societal que contempla as grandes ameaças ecológicas planetárias, não revelando diretamente ao sujeito a dimensão e gravidade do dano. ${ }^{40}$

Enfatizando a importância dessa diferenciação, na seqüência, Klaus Frey adverte que a maioria dos problemas ambientais de países em desenvolvimento como o Brasil se refere à ecologia do sujeito, prevalecendo ameaças que afetam diretamente a população local. E aponta como causa para a falta de ação global - que a comunidade internacional não se sente "suficientemente ameaçada do ponto de vista da ecologia do sujeito". Em virtude disso, ressalta-se a interdependência e/ou interconexão entre essas duas dimensões referidas por Hoffmann-Axthelm.

Embora, como já referido, a sustentabilidade depende de uma cidadania global, fundada na solidariedade, na diversidade, na democracia e nos direitos humanos, é a partir do local que as ações devem tomar forma. Vieira ratifica esse entendimento ao explicitar que a cidadania deve se dar com raízes locais, mas com consciência global. ${ }^{41}$ 
Nesse contexto, os Estados devem gradualmente ir aceitando essa maior importância dos governos locais, como agentes democráticos imprescindíveis em conjunto com a sociedade civil. Como afirma Dowbor, "os espaços locais podem abrir uma grande oportunidade para a sociedade retomar as rédeas do seu próprio desenvolvimento" ${ }^{\text {"2 }}$.

Essa força dos municípios constitui então um meio de aproximação com os cidadãos. As cidades tem ido em busca de parcerias e novas articulações sociais, em uma tentativa inclusive de recuperar seu espaço econômico e a dimensão de cidadania local.

Esse reforço do poder local representa uma importante evolução para a democracia. À democracia representativa, onde a cidadania se configura pelo voto, alia-se a democracia participativa, onde recaem aos próprios cidadãos as decisões atinentes à organização do seu cotidiano. Assim, tem-se que comunidades bem estruturadas podem dar margem à constituição de uma sociedade organizada capaz de transformar o seu meio. Nesse sentido,

\begin{abstract}
ultrapassando a tradicional dicotomia entre o Estado e a empresa, o público e o privado, surge assim com força o espaço público comunitário, e as nossas opções se enriquecem. Além disso, o surgimento dos sistemas modernos de comunicação muda radicalmente o conceito de isolamento da pequena cidade, da própria articulação dos diversos espaços. ${ }^{43}$
\end{abstract}

Na formulação de Milton Santos ${ }^{44}$, aquilo que globaliza separa. É o local que permite a união. Isso significa que a transferência da cidadania para níveis mais amplos e distantes do cidadão faz com que ela se dilua no esquecimento, acabando com o espaço de expressão social do indivíduo. Na linha de John Friedmann, é essencial o empowerment ${ }^{45}$, ou a recuperação, pelo espaço local, da cidadania. Essa concepção exige a mobilização a partir da base juntamente com a transformação do poder social em poder político. Esse "empoderamento" político pode ocorrer a partir do momento em que as aspirações da sociedade se voltam das preocupações privadas para as coletivas, envolvendo a luta por inclusão e o aumento das oportunidades de auto-desenvolvimento.

A base da ação, segundo Milton Santos, deve ser o espaço compartilhado no cotidiano, que precisa ser reconstituído. Porém, não em uma visão de "small is beautiful", mas por meio da reorganização dos espaços locais com os demais que compõem a sociedade complexa. ${ }^{46}$ Octavio lanni exprime esta idéia de forma poética: "o todo parece uma expressão diversa, estranha, alheia às partes. E estas permanecem fragmentadas, dissociadas, reiterandose aqui ou lá, ontem ou hoje, como que extraviadas, em busca de seu lugar" ${ }^{27}$.

O reforço da autonomia municipal é relevante para uma gestão coerente. A administração local deveria assumir o papel de catalisadora das forças locais em torno de objetivos da comunidade. Uma comunidade participativa e organizada em torno de seus interesses contribuiria para a estabilização do próprio governo central. 
Assim, merece atenção à questão municipal, analisando-a a partir da Constituição Federal de 1988 quanto à sua competência legislativa, sua autonomia e como estes instrumentos podem contribuir para a implementação de políticas públicas ambientais localizadas.

Vale ressaltar, aqui, que o Município, enquanto parte integrante do Estado Federativo brasileiro, encontra-se atrelado aos princípios constitucionais, dentre eles o princípio da precaução. Suas ações, assim, devem estar direcionadas, dentro de suas competências, à promoção do desenvolvimento sustentável.

Mas para que seja possível ter a exata compreensão e, quem sabe, delimitação das atribuições municipais, principalmente naquilo em que diz respeito ao meio ambiente, não se pode deixar de examinar o sistema constitucional brasileiro de repartição de competências. A Constituição Federal adota o sistema de "competências ou poderes reservados ou enumerados" 48 para União e Municípios. Ao Estado caberá o remanescente, conforme consubstanciado no artigo 25, parágrafo $1^{\circ}$ da Constituição Federal.

Segundo Meirelles, decorre desse sistema, por exemplo, que a manifestação expressa e privativa da competência municipal repele a de qualquer outro ente estatal. No entanto, sobre a competência implícita do município prevaleceria a competência expressa estadual ou federal, mas se a competência estadual também for implícita, ao município dar-se-ia a preferência. $^{49}$

Sendo as competências comuns às três esferas, surgem alguns impasses. Certos autores como Meirelles acreditam que neste caso, e quando houver área de ação livre para todas as entidades, deveria haver prevalência da maior para a menor. Dessa maneira, Andreas Krell ${ }^{50}$ adverte que haveria contradição do constituinte. Este, embora tenha optado pelo federalismo enquanto forma de organização do Estado brasileiro, ao mesmo tempo impediu que a descentralização se consolidasse de forma efetiva. A divisão de competências da Constituição Federal $^{51}$ destinou aos Municípios poucas matérias em termos de legislação, bem como em nenhuma hipótese concedeu a competência plena.

O cerne da competência administrativa municipal está no artigo 30, inciso I, da Constituição Federal com a discriminação das matérias nos incisos que seguem (II-IX). Tal dispositivo menciona que cabe aos municípios "legislar sobre assuntos de interesse local". Sobre o entendimento de interesse local, Meirelles conclui que se caracterizaria pela predominância do interesse municipal frente ao estadual e federal. E argumenta, com uma abordagem ampliada das competências municipais, que "não há assunto municipal que não seja reflexamente de interesse estadual e nacional. A diferença é apenas de grau e não de substância"52. No mesmo sentido, assevera Santana que

Parece-nos de que outro modo não se poderia imaginar o âmbito de ação municipal. É claro que o Município está situado dentro de um dado Estado e esse dentro da Federação Brasileira, ao que formam o todo, formam a união indissolúvel e, não há antinomia entre 
interesses locais e interesses gerais. $O$ traço que torna diferente 0 interesse local do interesse geral é a predominância, jamais a exclusividade, como já aqui afirmado. ${ }^{53}$

O reforço da autonomia municipal tornar-se-ia, então, relevante a uma gestão que almeja o fortalecimento da democracia. Nenhuma outra instância de poder ofereceria tão alto potencial de organização democrática participativa. Afinal, quanto mais atuante o Município, menos problemas terão o Estado e a União. Isso porque, como decorrência desse resgate do local, poder-se-ia observar a restituição ao cidadão do direito de decidir. Explicando em parte esse fenômeno, Lima de Matos defende:

O mais importante é que uma norma municipal tem condições de atender às necessidades locais, muitas vezes diferentes das necessidades nacionais ou regionais; sendo burilada no local onde produzirá seus efeitos, terá uma maior oportunidade de ouvir os anseios sociais e, por isso, a norma alcançará o interesse público em questão. ${ }^{54}$

Além disso, sendo as decisões tomadas com a participação dos interessados e sendo próximas desses, aumenta 0 sentimento de pertencimento àquela comunidade. Nenhuma outra instância de poder oferece tão alto potencial de organização democrática participativa, haja vista que nos municípios os atores sociais se conhecem, as políticas públicas podem ser integradas e os resultados, com impacto direto na vida das pessoas, se tornam visíveis.

Sendo o Município a menor unidade federativa, está mais próximo dos problemas e dos instrumentos legais de atuação. Assim, como gestor do interesse comunitário, poderá implementar uma política ambiental que promova a sustentabilidade. Ademais, em um país de tão grandes dimensões como o Brasil, direcionar a atuação aos Estados e à União impossibilitaria a concretização do bem-estar coletivo. Nesse aspecto reside a importância da competência suplementar legislativa do Município, prevista no artigo 24 da Constituição Federal, que irá adaptar lei federal ou estadual à realidade local.

Ao declarar, no artigo 23, inciso VI da Constituição, a proteção ambiental como competência comum, quis o legislador unificar a atuação nesta área, construindo um padrão mínimo para que os entes federados enfrentem estes problemas. Na lição de Machado, "em matéria ambiental como em todos os campos da Administração Pública de pouca valia será a ação compartimentalizada e isolada em suas manifestações" $" 55$. O fim último de qualquer política municipal deve ser o bem-estar de seus habitantes, com a incessante busca pelo equilíbrio social, ao que se pode denominar como função social dos municípios.

Isso não significaria a aplicação de modelos prontos e engessados, mas a simples harmonização das políticas nas regiões, para que pudessem ser alcançados os objetivos da Agenda 21 de um desenvolvimento sustentável. Portanto, cada Município deveria implementar as políticas ambientais de acordo com a sua realidade específica, haja vista a diversidade de problemas e de potenciais entre as localidades. 
Uma importante característica da Constituição Federal de 1988 refere-se ao fortalecimento, ao menos teoricamente, da autonomia Municipal nos aspectos político, administrativo, financeiro, tributário e legislativo. Teoricamente porque a autonomia financeira, como é notório, ainda não foi alcançada, o que limita a capacidade de auto-gestão municipal, tornando-a ineficiente.

Os princípios básicos que orientam as administrações municipais
ainda hoje são fortemente influenciadas por uma lógica clientelista
e altamente subordinada aos interesses das oligarquias locais. O
papel dos governos municipais era extremamente limitado,
restringindo-se suas responsabilidades às pequenas obras de
infra-estrutura, conservação de ruas e estradas, praças etc., ou de
políticas assistencialistas.

Em virtude da escassez de recursos financeiros e, por vezes, técnicos dos Municípios, Santos Júnior ${ }^{57}$ chama a atenção ao dilema da gestão local na perspectiva neoliberal. Governos municipais podem tornar-se dependentes estruturais do setor privado, que detêm as condições necessárias para a governabilidade na ordem econômica e social. Dessa dependência pode advir o predomínio de interesses de um determinado grupo em detrimento dos interesses coletivos. Outras vezes, ainda, a dependência estará nas mãos de empresas estrangeiras que sequer conhecem a realidade dos atores sociais locais.

Nesse contexto, estar-se-ia pondo em risco a autonomia do poder público local em face dos interesses particulares. Santos Júnior expõe seus temores quanto ao processo de descentralização ao afirmar que

[...] a descentralização poderia pôr em risco a capacidade do Estado de coordenar as políticas públicas a partir de objetivos mais inclusivos e de diagnósticos mais gerais, na medida em que atores privados inseridos no mercado teriam mais força para se apropriar de partes do aparelho estatal no âmbito municipal e impor seus interesses particulares. ${ }^{58}$

Contudo, é justamente em razão desse temor que é preciso reforçar a cidadania, permitindo à comunidade que tenha voz nas decisões, bem como que possam cobrar legitimamente uma postura diferenciada do poder público local. Ao se ter uma sociedade com voz ativa, participativa, fiscalizadora, capaz de se estruturar em redes, o poder local não mais correrá o risco de ser subjugado aos interesses do mercado. Ademais, a descentralização das verbas é essencial para o desenvolvimento de políticas locais.

O processo de democratização ambiental, segundo Henrique Leff, contempla "um amplo processo de transformações sociais. E segue argumentando que o Ambientalismo mobiliza a participação da população na tomada de decisões que afetam as suas condições de existência, desencadeando a energia e a criatividade social para gerar uma nova cultura política e múltiplas opções de organização produtiva". ${ }^{59}$ 
Portanto, nas palavras de Augusto de Franco, para que se tenha crescimento com desenvolvimento deve-se ter presente a idéia de cooperação e de cooperatividade sistêmica entre os mais variados atores sociais. ${ }^{60}$ Isso em busca de um novo padrão de relação Estado-Sociedade, que leva em consideração a existência e a importância de uma nova sociedade civil, integrada e participativa, com vistas ao desenvolvimento sustentável e integrado.

Cada vez mais o Poder Público municipal deverá contar com planos ambientais de maneira a integrar ações de desenvolvimento que sejam sustentáveis, atendendo à Agenda 21 e tendo acesso às fontes de financiamento. Defende Markus Brose que "em se mantendo as atuais tendências, as prefeituras deverão deixar cada vez mais o seu papel de "síndico da cidade" para atuar mais como agente de desenvolvimento humano" ${ }^{61}$

\section{CONCLUSÕES}

$\mathrm{Na}$ evolução para uma democracia ambiental participativa, a organização da sociedade civil no âmbito local é essencial. Devem-se facilitar às populações locais os meios necessários para que consigam desenvolver seu potencial autogestionário em práticas adequadas ecologicamente, a partir de seus próprios valores culturais, a partir da construção de seu capital social.

A descentralização permite, assim, que administrações locais sejam autônomas. Certamente, dentro de limites previamente estabelecidos, podendo definir quais são as prioridades na implantação de políticas públicas, a partir das demandas da sociedade.

Essa organização em sistemas participativos de gestão motivada pela descentralização gera instrumentos para o controle sobre as decisões dos governos. Postura essa que abre caminho para uma nova cultura em que se vislumbra a redistribuição do poder.

Essa sistemática ocasiona uma maior aproximação do cidadão, permitindo o enraizamento das políticas ambientais em um espaço que transcenda 0 da Administração Pública. Essa forte ligação estabelecida possibilita a criação de políticas públicas a longo prazo, haja vista não estarem vinculadas a um governo - que em um sistema democrático pode ser alterado a cada quatro anos - mas sim aos anseios e às decisões da comunidade local. A própria sociedade será partícipe na gestão das políticas de planejamento ambiental de sua cidade.

O que se propõe é, pois, uma gestão descentralizada e compartilhada entre os diferentes níveis de governo (verticalmente) e diferentes setores (horizontalmente), incluindo a iniciativa privada e população local, com o objetivo de serem desenvolvidos programas inter-setoriais com enfoque ambiental. A humanização do desenvolvimento passa necessariamente por essa reconstituição dos espaços comunitários. 
Para que se atinja um patamar de desenvolvimento que seja sustentável, é preciso recuperar a cidadania pelo espaço local. Cabe em particular aos Municípios estimular a participação e engajamento cívico, sendo este imprescindível ao fortalecimento de uma consciência ecológica.

Nesse sentido, acredita-se que, embora não seja a única maneira, a descentralização oferece grande contribuição. Com essa mudança de postura da sociedade, de coadjuvante a protagonista de sua própria história, a partir de uma conjugação de forças, será possível alcançar o propósito maior de uma gestão sustentável que garanta o direito das presentes e futuras gerações a um meio ambiente equilibrado.

\title{
IMPLEMENTATION OF THE ENVIRONMENTAL CITIZENSHIP FROM THE LOCAL POWER: A NECESSARY INTERLOCUTION TO THE SUSTAINABLE DEVELOPMENT
}

\begin{abstract}
The importance of the theme of environmental protection justifies its discussion and dissemination to the scientific community. In that sense, one proposes in this study to investigate the extent to which decentralization targeting a participatory democracy, with strong local structures - may encourage the creation of an environmental citizenship that refers to the sustainable development. The aim is thus to achieve the purpose of sustainable management that ensures the right of present and future generations to a balanced environment through the interaction between state and society.
\end{abstract}

Keywords: Citizenship - Decentralization - Democracy - Local Power -Sustainable Development.

\section{NOTAS}

Doutor Em Direito pela UNISINOS. Professor do Mestrado em Direito da Universidade de Santa Cruz do Sul (UNISC).

* Advogada, Especialista em Demandas Sociais e Políticas Públicas, Mestre em Direito., ambos pela Universidade de Santa Cruz do Sul (UNISC).

1 Na definição de BECK, Ulrich. La société du risque: sur la voie d'une autre modernité. Traduit de l'allemand par Laure Bernardi. Paris : Flammarion, 2001.

2 Doutrina em voga nas últimas décadas do séc. XX que favorece uma redução do papel do Estado na esfera econômica e social. O neoliberalismo se contrapõe à tendência anterior de aumento da intervenção governamental, em economias capitalistas, como resultado da adoção de políticas sociais de natureza assistencial e de políticas econômicas keynesianas.

3 WORLD Comission on Environment and Development. Our Common Future. Oxford: University Press Oxford, 1987, p.7.

4 MATEO, Ramón Martín. Tratado de derecho ambiental. 2 vols. Madrid: Editorial Trivium, 1991, p. 384-385. 
5 Em uma visão antropocêntrica que precisa ser rechaçada.

6 AVRITZER, Leonardo. Teoria democrática, esfera pública e participação local. Sociologias, Porto Alegre, ano 1, n. 2, p. 18-43, jul/dez 1999, p. 27.

7 SOUZA, Nelson Mello e. Educação ambiental - dilemas da prática contemporânea. Rio de Janeiro: Thex, 2000, p. 85-86.

8 DERANI, Cristiane. Direito ambiental econômico. 2. ed. São Paulo: Max Limonad, 2001, p. 134.

9 FREY, Klaus. A dimensão político-democrática nas teorias de desenvolvimento sustentável e suas implicações para a gestão local. Revista Ambiente e Sociedade, Campinas, n. 9, p. 1-27, jul/dez. 2001.

10 Neste sentido, ver DRYSEK, J. Ecology and discursive democracy: beyond liberal capitalism and the administrative state. Capitalism, nature, socialism, Vol. 3, n. 2, p. 18-42, 1992, p. 19 e MASON, M. Environmental democracy. London: Earthscan, 1999, p. 34.

11 DERANI, op. cit., p. 132.

12 Milton Santos, em sua obra Pensando o espaço do homem, procura, de certa maneira, responder a este questionamento, mas não deixa claro os procedimentos a serem seguidos. (SANTOS, Milton. Pensando o espaço do homem. São Paulo: Hucitec, 1992)

13 MILARÉ, Edis. Direito do ambiente: doutrina, prática, jurisprudência, glossário. 2. ed. São Paulo: Ed. Revista dos Tribunais, 2001, p. 49.

14 DERANI, op. cit. , p. 122.

15 FREY, op. cit., p. 5.

16 NUSDEO, Fábio. Desenvolvimento e ecologia. São Paulo: Saraiva, 1975, p. 94.

17 SACHS, I. Ecodesenvolvimento. Crescer sem destruir. São Paulo: Vértice, 1986, p. 115.

18 FREY, op. cit., p. 9.

19 DERANI, op. cit., p. 123.

20 FREY, op. cit, p. 11.

21 DRYSEK, J. Strategies of ecological democratization. In: LAFFERTY, W. ; MEADOWCROFT, J. (Orgs.) Democracy and the environment: problems and prospects. Cheltenham/Brookfield: Elgar, 1996, p. 108.

22 REILLY, Charles A. Redistribuição de direitos e responsabilidades - cidadania e capital social. In: PEREIRA, L.C.B.; GRAU, N.C. (Orgs.) O público não-estatal na reforma do Estado. Rio de Janeiro: Fundação Getúlio Vargas, 1999, p. 413.

23 LEITE, José R. Morato; AYALA, Patryck de Araújo. Direito ambiental na sociedade de risco. 2. ed. Rio de Janeiro: Forense Universitária, 2004, p. 303-304.

24 VIEIRA, Liszt. Cidadania e controle social. In: PEREIRA, L.C.B.; GRAU, N.C. (Orgs.) $O$ público não-estatal na reforma do Estado. Rio de Janeiro: Fundação Getúlio Vargas, 1999, p. 216.

25 LEITE, J. R. M.; AYALA, P. A., op. cit., p. 311.

26 BARACHO, José A. de Oliveira. Teoria geral da cidadania. São Paulo: Saraiva, 1995, p. 23.

27 Essa limitação da cidadania ao mero aspecto político é atualmente rechaçada por diversos autores, mas principalmente por aqueles que acreditam na viabilidade de concretização de uma cidadania ambiental.

28 LEITE, J. R. M.; AYALA, P. A., op. cit., p. 305.

29 VIEIRA, op. cit., p. 249.

$30 \quad$ LEITE, J. R. M.; AYALA, P. A., op. cit. , p. 317.

31 LEITE, J. R. M.; AYALA, P. A., op. cit., p. 316.

32 SÁlZ, Ángel Valencia. Democracia, ciudadanía y ecologismo político. Revista de Estúdios Políticos. Madri: Centro de Estúdios Constitucionales, out/dez. 1997, n. 102, p. 89.

33 LEITE, J. R. M.; AYALA, P. A., op. cit., p. 318.

34 REILLY, op. cit., p. 413.

35 ANDRADE, Vera Pereira de. Cidadania: do direito aos direitos humanos. São Paulo: Acadêmica, 1993, p. 126.

36 SANTOS, Boaventura de Souza. Pela mão de alice. Porto: Afrontamento, 1994, p. 42.

37 BOFF, Leonardo. Saber cuidar - ética do humano - compaixão pela Terra. 5. ed. Petrópolis: Vozes, 1999, p. 134.

38 NALINI, José Renato. Ética ambiental. Campinas: Millenium, 2001, p. XXV e XXVI.

39 MIRRA, Álvaro Luiz Valcry. Princípios fundamentais de direito ambiental. In: LEITE, J.R.M.; JÚNIOR, J.A.O. Cidadania coletiva. Florianópolis: Paralelo 27, 1996, p. 109-111, passim. 
No mesmo sentido ver MACHADO, P.A. Leme. Estudos de direito ambiental. São Paulo: Malheiros, 1994, p. 39-40.

40 FREY, op. cit., p. 17.

41 VIEIRA, Liszt. Os argonautas da cidadania. A sociedade civil na globalização. Rio de Janeiro: Ed. Record, 2001, p. 235.

42 DOWBOR, Ladislau. A reprodução social: propostas para uma gestão descentralizada. Petrópolis, Rio de Janeiro: Vozes, 1999, p. 41.

43 Ibidem, p. 42.

44 SANTOS, Milton. Espaço, ciência e técnica. São Paulo: Hucitec, 1995.

45 FRIEDMANN, John. Empowerment: the politics of alternative development. Blackwell: Cambridge, 1992. No prefácio dessa obra, o autor aponta a ênfase na autonomia de tomada de decisões por comunidades territorialmente organizadas como fundamental.

47 IANNI, Octavio. A idéia de Brasil moderno. Brasília: Brasiliense, 1992, p. 177.

48 MEIRELLES, Hely Lopes. Direito municipal brasileiro. 12. ed. São Paulo: Malheiros, 2001, p. 131.

49 O autor define como competências expressas aquelas literalmente expressas no texto constitucional, como as dos artigos 21 e 22, para a União, e os do artigo 30, para os Municípios. As implícitas são as que resultam como conseqüência lógica e necessária de um poder explícito, ou dos princípios adotados pela Constituição Federal. (MEIRELLES, H. L., op. cit., p. 131-134.)

50 KRELL, Andreas J. Discricionariedade administrativa e proteção ambiental: o controle dos conceitos jurídicos indeterminados e a competência dos órgãos ambientais. Porto Alegre: Livraria do Advogado, 2004, p. 93-103, passim.

51 Competências estabelecidas nos artigos 21 a 31 da Constituição Federal de 1988.

52 MEIRELLES, op. cit., p. 134-135.

53 SANTANA, Jair Eduardo. Competências legislativas municipais. Belo Horizonte: Del Rey, 1998, p. 120.

54 MATOS, Eduardo Lima de. Autonomia municipal e meio ambiente. Belo Horizonte: Del Rey, 2001, p. 126-127.

55 MACHADO, Paulo Afonso Leme. Direito ambiental. São Paulo: Malheiros, 1996, p. 73.

56 DESER, 1997, p. 14, apud BROSE, Markus. Fortalecendo a democracia e o desenvolvimento local: 103 experiências inovadoras no meio rural gaúcho. Santa Cruz do Sul: EDUNISC, 2000, p. 61-62.

57 SANTOS JR, Orlando Alves dos. Democracia e governo local: dilemas da reforma municipal no Brasil. Rio de Janeiro: Revan/FASE, 2001, p. 29-52, passim.

58 Ibidem, p. 46

59 LEFF, Henrique. Ecologia, capital e cultura: racionalidade ambiental, democracia participativa e desenvolvimento sustentável. Trad. Jorge Esteves da Silva. Blumenau: Ed. da FURB, 2000, p. 371-372.

60 FRANCO, Augusto de. Pobreza e desenvolvimento local. Brasília: AeD, 2002, p. 80.

61 BROSE, Markus. Fortalecendo a democracia e o desenvolvimento local: 103 experiências inovadoras no meio rural gaúcho. Santa Cruz do Sul: EDUNISC, 2000, p. 70.

\section{REFERÊNCIAS}

ANDRADE, Vera Pereira de. Cidadania: do direito aos direitos humanos. São Paulo: Acadêmica, 1993.

AVRITZER, Leonardo. Teoria democrática, esfera pública e participação local. Sociologias, Porto Alegre, ano 1, n. 2, p. 18-43, jul/dez 1999.

BARACHO, José A. de Oliveira. Teoria geral da cidadania. São Paulo: Saraiva, 1995.

BECK, Ulrich. La société du risque: sur la voie d'une autre modernité. Traduit de l'allemand par Laure Bernardi. Paris : Flammarion, 2001. 
BOFF, Leonardo. Saber cuidar - ética do humano - compaixão pela Terra. 5. ed. Petrópolis: Vozes, 1999.

BROSE, Markus. Fortalecendo a democracia e o desenvolvimento local: 103 experiências inovadoras no meio rural gaúcho. Santa Cruz do Sul: EDUNISC, 2000.

DERANI, Cristiane. Direito ambiental econômico. 2. ed. São Paulo: Max Limonad, 2001.

DESER, 1997, p. 14, apud BROSE, Markus. Fortalecendo a democracia e o desenvolvimento local: 103 experiências inovadoras no meio rural gaúcho. Santa Cruz do Sul: EDUNISC, 2000.

DOWBOR, Ladislau. A reprodução social: propostas para uma gestão descentralizada. Petrópolis, Rio de Janeiro: Vozes, 1999.

DRYSEK, J. Ecology and discursive democracy: beyond liberal capitalism and the administrative state. Capitalism, nature, socialism, Vol. 3, n. 2, p. 18-42, 1992.

Strategies of ecological democratization. In: LAFFERTY, W. ; MEADOWCROFT, J. (Orgs.) Democracy and the environment: problems and prospects. Cheltenham/Brookfield: Elgar, 1996.

FRANCO, Augusto de. Pobreza e desenvolvimento local. Brasília: AeD, 2002.

FREY, Klaus. A dimensão político-democrática nas teorias de desenvolvimento sustentável e suas implicações para a gestão local. Revista Ambiente e Sociedade, Campinas, n. 9, p. 1-27, jul/dez. 2001.

FRIEDMANN, John. Empowerment: the politics of alternative development. Blackwell: Cambridge, 1992.

IANNI, Octavio. A idéia de Brasil moderno. Brasília: Brasiliense, 1992.

KRELL, Andreas J. Discricionariedade administrativa e proteção ambiental: o controle dos conceitos jurídicos indeterminados e a competência dos órgãos ambientais. Porto Alegre: Livraria do Advogado, 2004.

LEFF, Henrique. Ecologia, capital e cultura: racionalidade ambiental, democracia participativa e desenvolvimento sustentável. Trad. Jorge Esteves da Silva. Blumenau: Ed. da FURB, 2000.

LEITE, José R. Morato; AYALA, Patryck de Araújo. Direito ambiental na sociedade de risco. 2. ed. Rio de Janeiro: Forense Universitária, 2004.

MACHADO, Paulo Afonso Leme. Direito ambiental. São Paulo: Malheiros, 1996.

. Estudos de direito ambiental. São Paulo: Malheiros, 1994.

MASON, M. Environmental democracy. London: Earthscan, 1999.

MATEO, Ramón Martín. Tratado de derecho ambiental. 2 vols. Madrid: Editorial Trivium, 1991.

MATOS, Eduardo Lima de. Autonomia municipal e meio ambiente. Belo Horizonte: Del Rey, 2001. 
MEIRELLES, Hely Lopes. Direito municipal brasileiro. 12. ed. São Paulo: Malheiros, 2001.

MILARÉ, Edis. Direito do ambiente: doutrina, prática, jurisprudência, glossário. 2. ed. São Paulo: Ed. Revista dos Tribunais, 2001.

MIRRA, Álvaro Luiz Valcry. Princípios fundamentais de direito ambiental. In: LEITE, J.R.M.; JÚNIOR, J.A.O. Cidadania coletiva. Florianópolis: Paralelo 27, 1996.

NALINI, José Renato. Ética ambiental. Campinas: Millenium, 2001.

NUSDEO, Fábio. Desenvolvimento e ecologia. São Paulo: Saraiva, 1975.

REILLY, Charles A. Redistribuição de direitos e responsabilidades - cidadania e capital social. In: PEREIRA, L.C.B.; GRAU, N.C. (Orgs.) O público nãoestatal na reforma do Estado. Rio de Janeiro: Fundação Getúlio Vargas, 1999.

SACHS, I. Ecodesenvolvimento. Crescer sem destruir. São Paulo: Vértice, 1986.

SÁlZ, Ángel Valencia. Democracia, ciudadanía y ecologismo político. Revista de Estúdios Políticos. Madri: Centro de Estúdios Constitucionales, out/dez. 1997, n. 102.

SANTANA, Jair Eduardo. Competências legislativas municipais. Belo Horizonte: Del Rey, 1998.

SANTOS, Boaventura de Souza. Pela mão de alice. Porto: Afrontamento, 1994.

SANTOS, Milton. Espaço, ciência e técnica. São Paulo: Hucitec, 1995.

. Pensando o espaço do homem. São Paulo: Hucitec, 1992.

SANTOS JR, Orlando Alves dos. Democracia e governo local: dilemas da reforma municipal no Brasil. Rio de Janeiro: Revan/FASE, 2001.

SOUZA, Nelson Mello e. Educação ambiental - dilemas da prática contemporânea. Rio de Janeiro: Thex, 2000.

VIEIRA, Liszt. Cidadania e controle social. In: PEREIRA, L.C.B.; GRAU, N.C. (Orgs.) O público não-estatal na reforma do Estado. Rio de Janeiro: Fundação Getúlio Vargas, 1999.

. Os argonautas da cidadania. A sociedade civil na globalização. Rio de Janeiro: Ed. Record, 2001.

WORLD Comission on Environment and Development. Our Common Future. Oxford: University Press Oxford, 1987.

Recebido para publicação 25/06/2008

Aceito para publicação 14/01/2009 